\title{
Extracellular synthesis of silver nanoparticles using Aspergillus versicolor and evaluation of their activity on plant pathogenic fungi
}

\section{Elgorban $\mathrm{AM}^{1,2}$, Aref $\mathrm{SM}^{2}$, Seham $\mathrm{SM}^{2}$, Elhindi $\mathrm{KM}^{3}$, Bahkali $\mathrm{AH}^{1}$, Sayed $\mathrm{SR}^{4}$, Manal MA ${ }^{1}$}

\author{
${ }^{1}$ Botany and Microbiology Department, College of Science, King Saud University, Saudi Arabia. \\ ${ }^{2}$ Plant Pathology Research Institute, Agricultural Research Center, Giza, Egypt. \\ ${ }^{3}$ Plant Production Department, College of Food and Agricultural Sciences, King Saud University, Saudi Arabia. \\ ${ }^{4}$ Department of Zoology, College of Science, King Saud University, Saudi Arabia
}

Elgorban AM, Aref SM, Seham SM, Elhindi KM, Bahkali AH, Sayed SR, Manal MA 2016 Extracellular synthesis of silver nanoparticles using Aspergillus versicolor and evaluation of their activity on plant pathogenic fungi. Mycosphere 7(6), 844-852, Doi 10.5943/mycosphere/7/6/15

\begin{abstract}
In the current study, silver nanoparticles (Ag NPs) were synthesized using Aspergillus versicolor. The synthesized Ag NPs were characterized by UV-Vis spectrum, TEM, XRD, SEM, and EDS, which revealed that the synthesized NPs had a face-centred cubic similarity. The rapid synthesis of Ag NPs in fungal filtrate showed bright sunlight. The maximum absorbance of Ag NPs was observed at $620 \mathrm{~nm}$ which is a sign of Ag NPs. The TEM analysis revealed the spherical shape with the size ranged between 5 to $30 \mathrm{~nm}$ and EDS showed the presence of $\mathrm{Ag}$ at $3 \mathrm{kev}$. The antifungal activity of biogenic Ag NPs was evaluated against white mold (Sclerotinia sclerotiorum) and grey mould (Botrytis cinerea) in strawberry (Fragaria $x$ ananassa). The results showed that synthesized silver nanoparticles exhibit significant antifungal potential on both pathogens in a concentration-dependent manner. The maximum reduction in both fungi was observed at $150 \mathrm{ppm}$ of Ag NPs.
\end{abstract}

Key words - Aspergillus versicolor - biomass - grey mould - Sclerotinia sclerotiorum - silver nanoparticles

\section{Introduction}

Agricultural output is decreased worldwide year after year because of plant diseases. Millions have been expended in efforts to protect these plant diseases. Several techniques have been applied to control phytopathogenic fungi. The use of fungicides is the main widespread method to control the diseases (Zhang et al. 2007). In current years, environmental threats caused by excessive use of fungicides have been discussed extensively. Therefore, the scientist and researchers in the agricultural area are searching for alternatives in synthetic fungicides. As an alternative to agrochemicals, utilization of silver nanoparticles as antifungal agents has become more prevalent as advanced technologies make their manufacture more economical (Kim et al. 2012, Elgorban et al. 2016). One of the possible applications of $\mathrm{Ag}$ is in the control of plant pathogenic fungi. As silver has been shown various modes of inhibitory effect against several microorganisms (Jin-Hee et al. 2010). Thus, it could be utilized with comparative safety for management of several plant diseases as compared to agrochemicals (Kabir et al. 2011a, b). In earlier studies the eco-friendly properties 
and intense effects of $\mathrm{Ag}+$ have been shown. Major requirements for the possible utilization of $\mathrm{Ag}$ in management of plant disease involve the need for further studies on antimicrobial activities of several silver compounds against phytopathogenic fungi and to improve the efficiency of disease management (Kim et al. 2012). The green synthesis of silver nanoparticles is in the limelight in new nanotechnology (Gade et al. 2009, Elgorban et al. 2016, Shaban et al. 2015). The culture of fungi at large scale is simple, whereas, the bacterial system consists utilization of progressing instruments to achieve pure filtrate from colloidal broth. In the fungal system, it secrets extracellular enzymes, which have extra features in the downstream treatment and handling of biomass (Gade et al. 2008). In view of fungi properties, it may be exceedingly used for the fast and eco-friendly green synthesis of mineral NPs.

Green synthesis of Ag NPs by using several fungi such as the bioagent Trichoderma (Singh et al. 2011, Vahabi et al. 2011), Aspergillus (Patil et al. 2011, Li et al. 2013), and Fusarium (Anitha \& Palanivelu, 2011, Soni \& Prakash 2011) has been reported. Newly the antifungal activity of silver nanoparticles has been studied by several researchers (Panáček et al. 2009, Qian et al. 2013, Roy et al. 2013, Xu et al. 2013, Elgorban et al. 2016). Conversely, few studies are available on the antifungal activity of Ag nanoparticles against plant pathogenic fungi (Velmurugan et al. 2009, Kasprowicz et al. 2010, Lee et al. 2013). Strawberry (Fragaria ananassa) is one of the most extensively grown small fruit crops in the world. Botrytis cinerea and Sclerotinia sclerotiorum are responsible for severe economic losses (Williamson et al. 2007, Mertely \& Peres, 2009), in some places, the yield losses reaching to $90 \%$ (Ellis \& Grove 1982). Strawberry fruits have a very short postharvest life, gray mold caused by $B$. cinerea and white mold caused by $S$. sclerotiorum infection may occur and cause fruit decay.

Therefore, this study has been focused on synthesis of Ag NPs using Aspergillus versicolor and also the inhibitory effect of these silver nanoparticles against white mold (S. sclerotiorum) and grey mold (B. cinerea) in strawberry (Fragaria x ananassa) in vitro.

\section{Materials \& Methods}

\section{Isolation and identification of microorganisms}

\section{Aspergillus versicolor}

Aspergillus versicolor was isolated from soil obtained from the greenhouses, Riyadh, Saudi Arabia and was identified according to Benndorf et al. (2008).

\section{The pathogenic fungi}

Sclerotinia sclerotiorum and Botrytis cinerea were isolated from strawberry (Fragaria $x$ ananassa). The fungi were cultured in potato dextrose agar (PDA) medium. On the basis of cultural properties and microscopic observations, S. sclerotiorum and B. cinerea were identified as described (Ai-Rong et al. 2008; Chilvers \& du Toit 2006).

\section{Synthesis of silver nanoparticles}

To prepare silver nanoparticles, $A$. versicolor was grown aerobically in a liquid medium containing: glucose, $15.0 \mathrm{~g} ; \mathrm{KH}_{2} \mathrm{PO}_{4}, 7.0 \mathrm{~g}$; $\mathrm{K}_{2} \mathrm{HPO}_{4}, 2.0 \mathrm{~g}$; $\left(\mathrm{NH}_{2}\right) \mathrm{SO}_{4}, 1.0 \mathrm{~g} ; \mathrm{MgSO}_{4} \cdot 7 \mathrm{H}_{2} \mathrm{O}, 0.1 \mathrm{~g}$; and yeast extract, $1.0 \mathrm{~g}$. The Erlenmeyer flasks were inoculated with a spore suspension of $A$. versicolor and were incubated on an incubator shaker at $25^{\circ} \mathrm{C}(120 \mathrm{rpm})$. The biomass was collected after 7 days by filtration through the filter paper (Whatman No. 1), washed four times with sterilized distilled water to eliminate any medium component. The obtained biomass $(20 \mathrm{~g}$, fresh weight) was mixed with $150 \mathrm{~mL}$ of distilled water for $48 \mathrm{~h}$ at $25^{\circ} \mathrm{C}(120 \mathrm{rpm})$. The cell filtrate was detached from flasks by passing it through Whatman No. 1. For NPs synthesis, silver nitrate, 1 $\mathrm{mM}$ final concentration $(50$ or $100 \mathrm{~mL}$ ) was mixed with 50 or $100 \mathrm{~mL}$ of the cell filtrate in a flask and incubated at $35^{\circ} \mathrm{C}(120 \mathrm{rpm})$ in the dark for 5 days. Filtrates without the silver ion were served as control. All the tests were done in triplicates. 


\section{Characterization of Ag NPs}

The qualitative experiment for affirmation of Ag NPs was carried out with UV-vis spectroscopy. $1 \mathrm{~mL}$ of specimen aliquot from this bio transformed product was drawn after 24 post incubation with AgNO3 solution, and absorbance was noted by using Biochrom Anthos 2020 spectrophotometer wavelength range: $400-750 \mathrm{~nm}$, with 4 standard filters $(405,450,492,620$ $\mathrm{nm}$ ), including onboard software to examine the change in light absorption of the solution with rise in color intensity. The small amount of the dried precipitate was spared on carbon tap with stub. The specimen was subjected to SEM (JEOL, JSM-6380 LA, Japan). The intermediate shapes and size of the Ag NPs were measured by transmission electron microscopy (TEM). A drop of NPs suspension was put on a carbon-coated copper grid, dried in oven at $65 \mathrm{~h}$ for $24 \mathrm{~h}$. Micrographs were obtained in transmission electron microscope (JEOL Ltd., Akishima-shi, Japan) with 80- to $120-\mathrm{kV}$ accelerating voltage at $0.23-\mathrm{nm}$ resolution.

\section{Antifungal activity of silver nanoparticles on Sclerotinia sclerotiorum and Botrytis cinerea}

In vitro test was conducted on PDA treated with various concentrations $(25,50,100$, and $150 \mathrm{mg} / \mathrm{L}$ ) of silver nanoparticles. Five $\mathrm{mL}$ of silver nanoparticles having various concentrations was poured into PDA prior to plating in a Petri plate. PDA containing Ag NPs was incubated at $20 \pm 2^{\circ} \mathrm{C}$. After 2 days of incubation, agar disc $(5 \mathrm{~mm})$ containing fungi were inoculated simultaneously at the center of each Petri plates containing Ag NPs, followed by incubation at $20 \pm 2^{\circ} \mathrm{C}$ for 5 days. The following formula was utilized for the calculation of the inhibition rate (\%).

$$
\text { Inhibition rate } \%=\frac{\mathrm{M}-\mathrm{m}}{\mathrm{M}} \times 100
$$

Where $\mathrm{M}$ is the radial growth of fungal mycelia on the control plate and $\mathrm{m}$ is the radial growth of fungal mycelia on the plate with silver nanoparticles.

\section{Results and discussion}

\section{UV-vis spectrum of Ag NPs}

Aspergillus versicolor was grown on culture liquid medium. The biomass was collected to obtain mycelia free cell filtrate. It was observed that the color was changed after the addition of silver nitrate to free cell filtrate by visual notice in the culture. The color of cell filtrate containing silver nitrate changed from colorless to yellow after $10 \mathrm{~min}$ and finally to brown. This change in color refers to the formation of Ag NPs in the solution, while free cell silver nitrate did not display any visual color change (Fig. 1). The increase in the color density also depends on the size of the synthesized silver nanoparticles. Smitha et al. (2009) confirmed that the color turn during metal NPs synthesis is due to the collective vibration of free conduction electrons stimulated by an interactive electromagnetic field that called surface plasmon peak. The UV absorption spectral studies were done to confirm the formation of Ag NPs using A. versicolor (Fig. 2). The absorption peak in the UV spectrum equal to the surface plasmon resonance, the maximum synthesis of $\mathrm{Ag}+$ was shown at $620 \mathrm{~nm}$ where maximum peak was found (Bhimba et al. 2014, Ninganagouda et al. 2014).

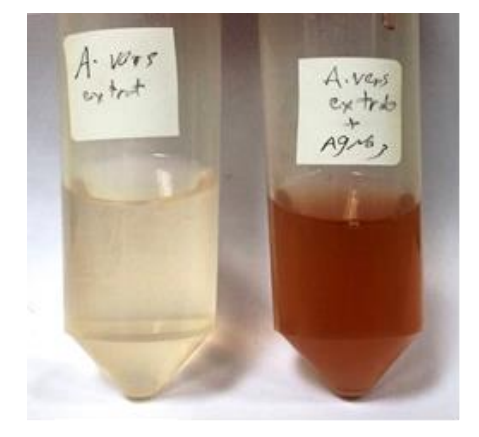

Fig. 1 - Color of A. versicolor free cell extract wthiout $\mathrm{AgNO}_{3}$ (A) and with $\mathrm{AgNO}_{3}(\mathrm{~B})$ 


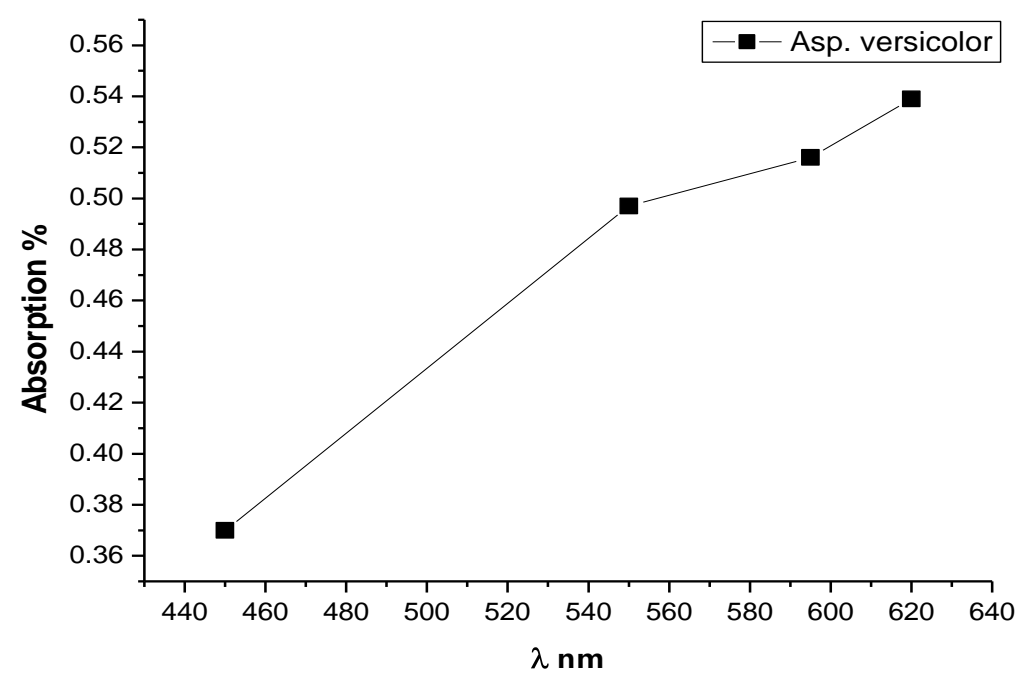

Fig. 2 - UV-visible spectra recorded for the reaction of A. versicolor cell filtrate with AgNO3 solution.

\section{Transmission electron microscopy (TEM)}

Transmission electron microscopy method was utilized to conceive the morphology of Ag NPs synthesized. As shown in Fig. 3, revealed individual instead of a number of assembled spherical Ag NPs. The NPs were not in direct contact even in the assembles and were enclosed by a thin layer of organic materials (Jagtap \& Bapat 2013). The sizes of the particle histogram of Ag NPs are shown in Fig. 4. The results revealed that there was difference in both the average size and the particle size. The size of the particles was found in the ranges between 5 to $30 \mathrm{~nm}$. The particle distribution presented in Fig 4, displays that the maximum percentage noticed of the particle size are in the range of 5 to $10 \mathrm{~nm}$. Shekhar et al. (2014) revealed that the shape and size of the green synthesized $\mathrm{Ag}$ NPs depend on the $\mathrm{pH}$ and temperature of the medium as well as the microorganisms. The difference size of Ag NPs which produce by Aspergillus species have been reported as Aspergillus terreus (10-19 nm) Eepsita at al. 2014), Aspergillus niger (5- $35 \mathrm{~nm})$ (Lamabam and Joshi, 2015), Aspergillus foetidus (20-40 nm) (Roy et al. 2013), and Aspergillus parasiticus (less than $50 \mathrm{~nm}$ ) (Moazeni et al. 2014).

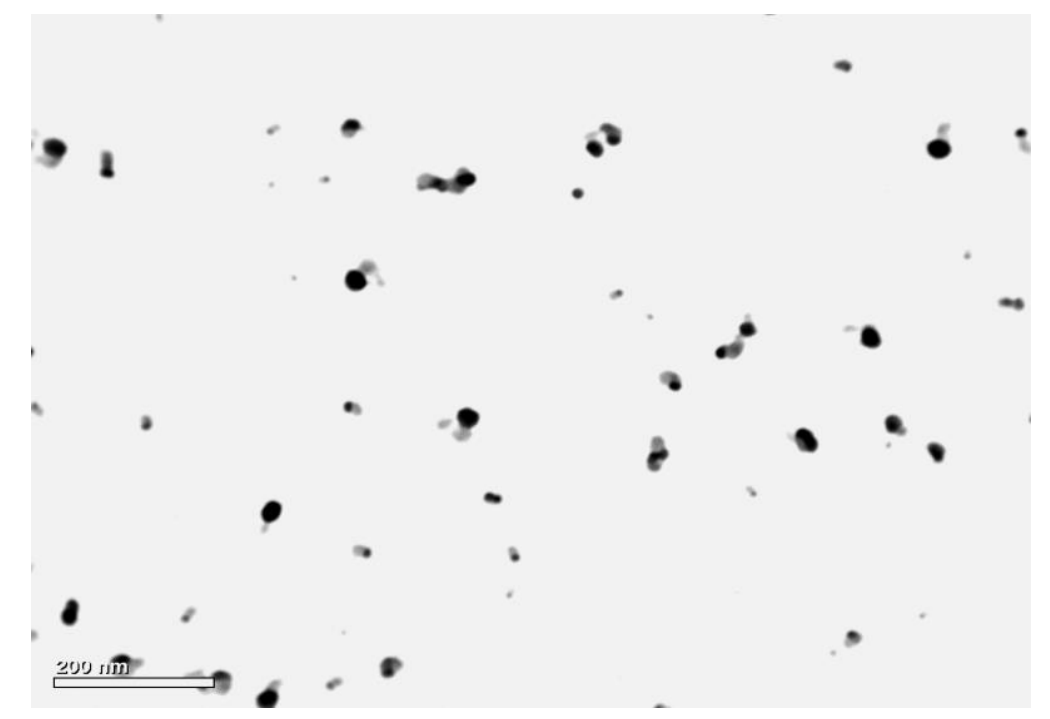

Fig. 3 - TEM micrographs of silver nanoparticles synthesized A. versicolor 


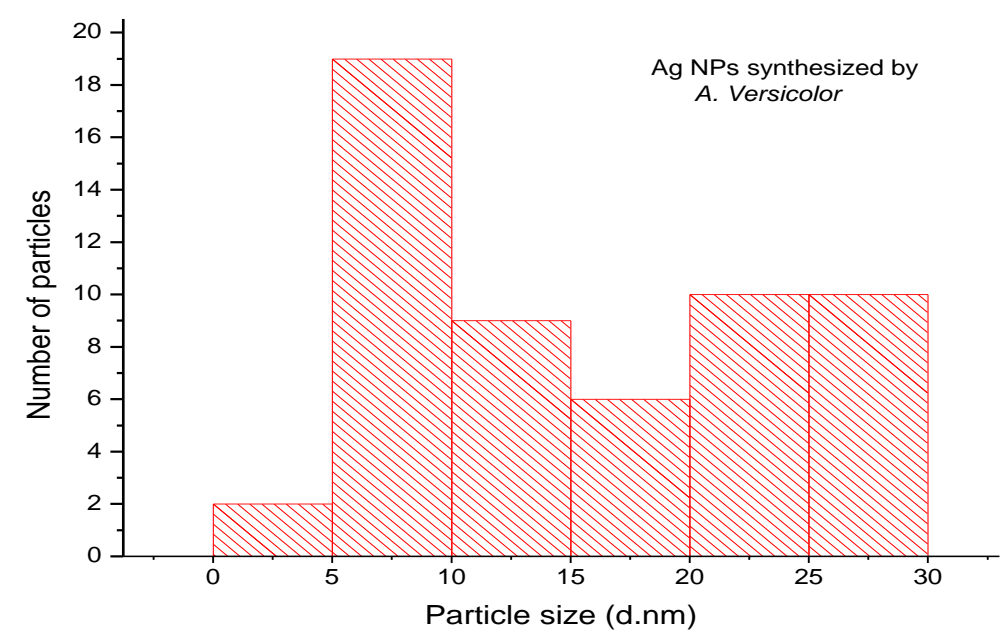

Fig. 4 - A particle size distribution histogram of synthesized Ag NPs determined from Transmission Electron Microscopy (TEM) image.

\section{Scanning electron microscope (SEM) and energy dispersive X-ray analysis (EDS)}

SEM images display irregular and spherical shaped silver nanoparticles with diverse sizes (Fig. 5). It was observed that there were presences of several silver nanoparticles clusters, which might be attributed to the aggregation of nanoparticles formed throughout specimen preparation (Puchalski et al. 2007, Selvi \& Sivakumar 2012). Fig. 6 showed the EDS analysis of the NPs. The elemental structure of powdered specimen was determined using SEM equipped with an EDS detector. The energy dispersive X-ray analysis displayed the strong signal at about $3 \mathrm{keV}$ of the Ag regions due to surface plasma resonance. Also, the ghostly signals for oxygen and carbon were noticed which indicated that the extracellular organic moieties from culture filtrate were adsorbed on the surface of the NPs (Bhainsa \& D'Souza, 2006, Lamabam \& Joshi 2015).

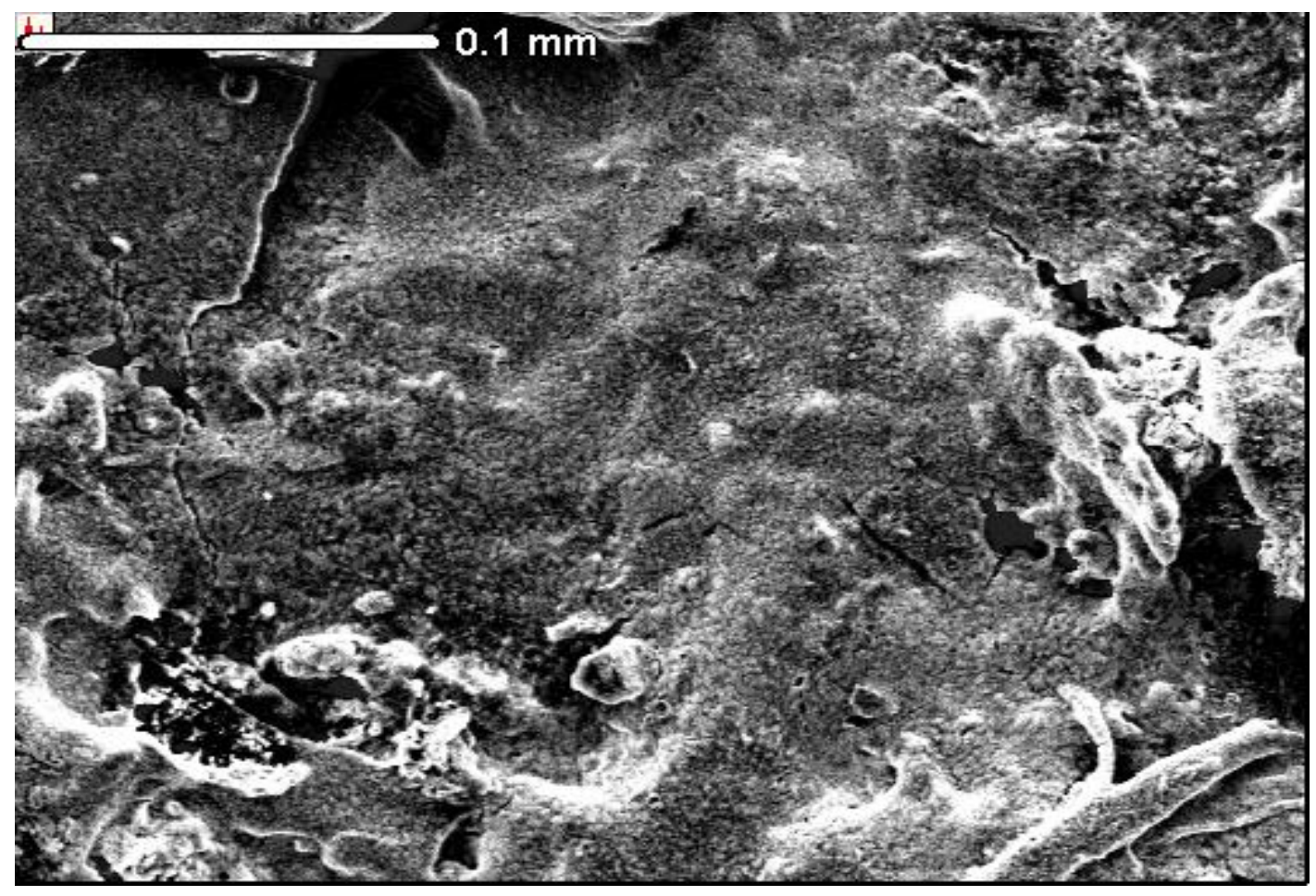

Fig. 5 - Scanning electron microscopy of Ag NPs formed by A. versicolor 


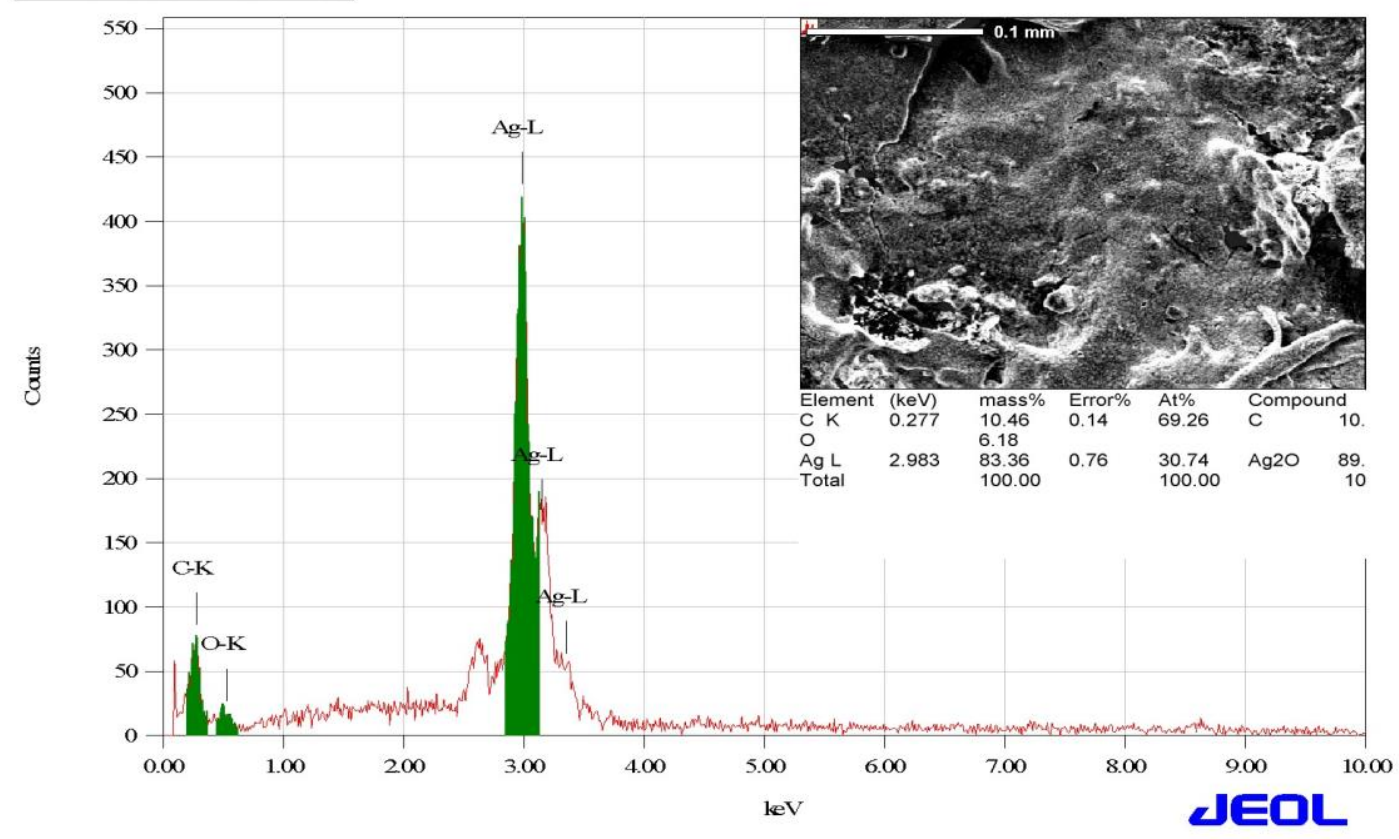

Fig. 6 - EDS spectrum recorded of silver nanoparticles formed by A. versicolor

\section{Antifungal activity of silver nanoparticles on Sclerotinia sclerotiorum and Botrytis cinerea}

The inhibition effect of silver nanoparticles at various concentrations was analyzed in PDA (Table 1). The maximum inhibition of fungal growth was observed at $150 \mathrm{ppm}$. The highest value of inhibition was noticed against $B$. cinerea at $150 \mathrm{ppm}$ that produced $80.38 \%$ inhibition in fugal growth with 72.4, 382.8 and 2.3 \pm 3.9 ED50, ED95, and Slope \pm SE, respectively. Also, the highest level of growth inhibition of $S$. sclerotiorum was observed at $150 \mathrm{ppm}$ giving $74.39 \%$ reduction in fungal growth with 96.5 (ED50), 591.1 (ED95), and 2.1 \pm 4.1 (Slope \pm SE). The present study demonstrated that silver nanoparticles were found to be very effective against both plant pathogenic fungi. The results suggested that silver nanoparticles have the capacity to inhibit the growth of $S$. sclerotiorum and B. cinerea. The effect was observed in a concentration dependent manner in both fungi. The both fungi showed maximum inhibition at $150 \mathrm{ppm}$ Ag NPs concentration. The inhibition was increased as the concentration of silver nanoparticles increases. This high antifungal activity of silver nanoparticles is probably related to the high intensity at which Ag NPs solution were capable of state and agglutinate to fungal hyphe and to deactivate plant pathogenic fungi. There are many mechanisms of inhibitory effect of Ag+ on microorganisms, such as DNA loses its ability to replicate (Feng et al. 2000), resulting in inactivated expression of ribosomal subunit proteins, instead of some other enzymes and cellular proteins necessary to the adenine triphosphate production (Yamanaka et al. 2005). In addition, it has been supposed that silver ion primarily affects the membrane-bound enzymes function, for instance those in the respiratory chain (Bragg \& Rainnie 1974, McDonnell \& Russell 1999).

Table 1 Antifungal activity of extracellular silver nanoparticles against plant pathogenic fungi (Inhibition \%)

\begin{tabular}{lcccccccc}
\hline \multirow{2}{*}{ Organisms } & \multicolumn{9}{c}{ Concentration $(\mathbf{m g} / \mathbf{L})$} & & \multirow{2}{*}{ ED50 } & \multirow{2}{*}{ ED95 } & Slpoe \pm SE \\
& $\mathbf{0}$ & $\mathbf{2 5}$ & $\mathbf{5 0}$ & $\mathbf{1 0 0}$ & $\mathbf{1 5 0}$ & & & \\
\hline S. sclerotiorum & 82.00 & 15.24 & 22.87 & 42.07 & 74.39 & 96.5 & 591.1 & $2.1 \pm 4.1$ \\
B. cinerea & 79.00 & 16.77 & 33.54 & 58.23 & 80.38 & 72.4 & 382.8 & $2.3 \pm 3.9$ \\
\hline
\end{tabular}


In outline, silver nanoparticles have great potential antifungal effects of both fungi tested, perhaps throughout the demolition of membrane solidity; consequently, it was concluded that silver nanoparticles have significant antifungal activity.

\section{Disclosure statement}

No potential conflict of interest was reported by the authors.

\section{Acknowledgments}

The authors extend their sincere appreciations to the Deanship of Scientific Research at King Saud University for its funding this Prolific Research Group (PRG-1437-34).

\section{References}

Ai-Rong W, Wen-Wei L, Xiao-Ting C, Guo-Dong L, Jie Z, Zong-Hua W. 2008 - Isolation and identification of Sclerotinia stem rot causal pathogen in Arabidopsis thaliana. Journal of Zhejiang University-Science B 9, 818-822.

Anitha TS, Palanivelu P. 2011 - Synthesis and structural characterization of polydisperse silver and multidisha- ped gold nanoparticles using Fusarium oxysporum MT- CC 284. Digest Journal of Nanomaterials and Biostructures 6, 1587-1595.

Benndorf D, Müller A, Bock K, Manuwald O, Herbarth O, von Bergen M. 2008 - Identification of spore allergens from the indoor mould Aspergillus versicolor. Allergy 63, 454-60.

Bhainsa KC, D'Souza SF. 2006 - Extracellular biosynthesis of silver nanoparticles using the fungus Aspergillus fumigatus. Coll Surf B: Biointerfaces 47,160-164.

Bhimba VB, Smriti G, Usha N. 2014 - Silver nanoparticles synthesized from marine fungi Aspergillus oryzae. International Journal of ChemTech Research 15, 68-72.

Bragg PD, Rainnie DJ. 1974 - The effect of silver ions on the respiratory chains of Escherichia coli. Canadian Journal of Microbiology 20, 883-889.

Chilvers MI, du Toit LJ. 2006 - Detection and identification of Botrytis species associated with neck rot, scape blight, and umbel blight of onion. Online. Plant Health Progress doi:10.1094/PHP-1127-01-DG.

Eepsita P, Nilotpala P, Lala BS, Prasanna KP. 2014 - Controlled synthesis of gold nanoparticles using Aspergillus terreus IF0 and its antibacterial potential against gram negative pathogenic bacteria. Journal of Nanotechnology, Article ID 653198, 9 pages. doi: $10.1155 / 2014 / 653198$.

Elgorban AM, El-Samawaty AM, Yassin MA, Sayed SR, Adil SF, Elhindi KM, Marwa B, Khan M. 2016 - Antifungal silver nanoparticles: synthesis, characterization and biological evaluation. Biotechnology \& Biotechnological Equipment 1, 56-62.

Ellis MA, Grove GG. 1982 - Fruit rots cause losses in Ohio strawberries, Ohio Re. Res. Dev., 67, 3-4.

Feng QL, Wu J, Chen GQ, Cui FZ, Kim TN, Kim JO. 2000 - A mechanistic study of the antibacterial effect of silver ions on Escherichia coli and Staphylococcus aureus. Journal of Biomedical Materials Research Part B: Applied Biomaterials 52, 662-668.

Gade A, Bonde P, Ingle AP, Marcato PD, Durán N, Rai MKJ. 2008 - Exploitation of Aspergillus niger for synthesis of silver nanoparticles. Journal of Biobased Materials and Bioenergy 2, 243-247.

Gade A, Ingle A, Bawaskar M, Rai M. 2009 - Fusarium solani: a novel biological agent for the extracellular synthesis of silver nanoparticles. Journal of Nanoparticle Research 11, 20792085.

Jagtap UB, Bapat VA. 2013 - Green synthesis of silver nanoparticles using Artocarpus heterophyllus Lam. Seed extract and its antibacterial activity. Industrial Crops and Products, $46,132-137$ 
Jin-Hee J, Sang-Woo K, Ji-Seon M, Young-Jae K, Kabir L, Kyoung SK, Youn SL. 2010 - The effect of nano-silver liquid against the white rot of the green onion caused by Sclerotium cepivorum. Mycobiology 38, 39-45.

Kabir L, Sang-Woo K, Jin HJ, Yun SK, Kyoung SK, Youn SL. 2011a - Inhibition Effects of silver nanoparticles against powdery mildews on cucumber and pumpkin. Mycobiology, 39, 2632.

Kabir L, Sang-Woo K, Jin HJ, Yun SK, Kyoung SK, Youn SL. 2011b - Application of silver nanoparticles for the control of Colletotrichum species in vitro and pepper anthracnose disease in field. Mycobiology 39, (3), 194-199.

Kasprowicz MJ, Koziol M, Gorczyca A. 2010 - The effect of silver nanoparticles on phytopathogenic spores of Fusarium culmorum. Canadian Journal of Microbiology 56, 247-253.

Kim SW, Jin HJ, Kabir L, Yun SK, Ji SM, Youn SL. 2012 - Antifungal effects of silver nanoparticles (Ag NPs) against various plant pathogenic fungi. Mycobiology 40, 53-58.

Lamabam SD, Joshi SR. 2015 - Ultrastructures of silver nanoparticles biosynthesized using endophytic fungi. Journal of Microscopy and Ultrastructure 3, 29-37.

Lee K-J, Park SH, Govarthanan M, Hwang PH, Seo YS, Cho M, Lee WH. Lee JY, Kamala-Kannan S, Oh, BT. 2013 - Synthesis of silver nanoparticles using cow milk and their antifungal activity against phytopathogens. Materials Letters 105, 128-131.

Li G, He D, Qian Y, Guan B, Gao S, Cui Y, Yo-koyama K, Wang L. 2012 - Fungus mediated green synthesis of silver nanoparticles using Aspergillus terreus. International Journal of Molecular Sciences 13, 466-476.

McDonnell G, Russell AD. 1999 - Antiseptics and disinfectants: activity, action, and resistance. Clinical Microbiology Reviews 12, 147-179.

Mertely JC, Peres NA. 2009 - Botrytis fruit rot on gray mold of strawberry University of Florida. IFAS Extension p. 230.

Moazeni M, Shahverdi AR, Nabili M., Noorbakhsh F, Rezaie S. 2014 - Green synthesis of silver nanoparticles: The reasons for and against Aspergillus parasiticus. Journal of Nanomedicine 1, 267-272.

Ninganagouda S, Vandana R, Dattu S. 2014 - Characterization and biosynthesis of Silver nanoparticles using a fungus Aspergillus niger. International Letters of Natural Sciences 15, 49-57.

Panáček A, Kolář M, Večeřová R, Prucek R, Soukupová J, Kryštof V, Hamal P, Zbořil R, Kvítek L. 2009 - Antifungal activity of silver nanoparticles against Candida spp. Biomaterials 30, 6333-6340.

Patil HB, Borse SV, Patil DR, Patil UK, Patil HM. 2011 - Synthesis of silver nanoparticles by microbial method and their characterization. Archives of Physics Research 2, 153-158.

Puchalski M, Dąbrowski P, Olejniczak W, Krukowski P, Kowalczyk P, Polański K. 2007 - The study of silver nanoparticles by scanning electron microscopy, energy dispersive X-ray analysis and scanning tunnelling microscopy. Materials Science-Poland 25, 473-478.

Qian Y, Yu H, He D, Yang H, Wang W, Wan X, Wang L. 2013 - Biosynthesis of silver nanoparticles by the endophytic fungus Epicoccum nigrum and their activity against pathogenic fungi. Bioprocess and Biosystems Engineering 36, 1613-1619.

Roy S, Mukherjee T, Chakraborty S, Das TK. 2013 - Biosynthesis, characterization and antifungal activity of silver nanoparticles synthesized by the fungus Aspergillus foetidus Mtcc8876. Digest Journal of Nanomaterials and Biostructures 8, 197-205.

Selvi KV, Sivakumar T. 2012 - Isolation and characterization of silver nanoparticles from Fusarium oxysporum. Int. J. Curr. Microbiol. App. Sci. 1, 56-62.

Shaban RMS, Bahkali AH, Hirad AH, El-Metwally MA, Elgorban AM. 2015 - Antibacterial activity of biogenic silver nanoparticles produced by Aspergillus terreus. International Journal of Pharmacology 11, 858-863. 
Shekhar A, Soumyo M, Suparna M. 2014 - Size-controlled silver nanoparticles synthesized over the range 5-100 $\mathrm{nm}$ using the same protocol and their antibacterial efficacy. RSC Advances Blog 4, 3974-3983.

Singh P, Raja RB. 2011 - Biological synthesis and characterization of silver nanoparticles using the fungus Trichoderma harzianum. Asian Journal of Experimental Biology and Science 2, 4: 600-605.

Smitha SL, Philip D, Gopchandran KG. 2009 - Green synthesis of gold nanoparticles using Cinnamomum zeylanicum leaf broth. Spectrochimica Acta Part A: Molecular and Biomolecular Spectroscopy 74, 735-739.

Soni N, Prakash S. 2011 - Factors Affecting the Geometry of Silver Nanoparticles Synthesis in Chrysosporium tropicum and Fusarium oxysporum. American Journal of Nanotechnology 2, 112-121.

Vahabi K, Mansoori GA, Karimi S. 2011 - Biosynthesis of silver nanoparticles by fungus Trichoderma ressei. Inscience Journal 1, 65-79.

Velmurugan N, Kumar GG, Han SS, Nahm KS, Lee YS. 2009 - Synthesis and characterization of potential fungicidal silver nano-sized particles and chitosan membrane containing silver particles. Iranian Polymer Journal 18, 383-392.

Williamson BB, Tudzynski P, Tudzynski JAL, Vankan LM. 2007 - Botrytis cinerea the cause of grey mold disease. Molecular Plant Pathology 8, 561-580.

Xu Y, Gao C, Li X, He Y, Zhou L, Pang G, Sun S. 2013 - In vitro antifungal activity of silver nanoparticles against ocular pathogenic filamentous fungi. Journal of Ocular Pharmacology and Therapeutics 29, 270-274.

Yamanaka M, Hara K, Kudo J. 2005 - Bactericidal actions of a silver ion solution on Escherichia coli, studied by energy-filtering transmission electron microscopy and proteomic analysis. Applied and Environmental Microbiology 71, 7589-7593.

Zhang J. 2007 - The potential of a new fungicide fludioxonil for stem-end rot and green mold control on Florida citrus fruit. Postharvest Biology and Technology 46, 262-270. 